\title{
PWR Effect On Crack Initiation Under Equi-biaxial Loading
}

\author{
Cédric Gourdin ${ }^{I-2, *}$, Hager Dhahri ${ }^{1-2}$, Grégory Perez ${ }^{1}$, Stéphan Courtin ${ }^{3}$, Jean-Christophe Le Roux ${ }^{4}$ and Habibou \\ Matirouman ${ }^{2}$ \\ ${ }^{1}$ DEN-Services d'Etudes Mécaniques et Thermiques (SEMT), CEA, University of Paris-Salay, F-91191 Gif-sur-Yvette, France \\ ${ }^{2}$ IMSIA, UMR 9219, CNRS, CEA, EDF, UNIVERSITY OF PARIS-SACLAY, 91762, Palaiseau, Cedex France \\ ${ }^{3}$ FRAMATOME SAS, Tour AREVA F-92084 Paris La Défense, France \\ ${ }^{4}$ EDF, R\&D, Site des Renardières, F-77818 Moret sur Loing Cedex, France
}

\begin{abstract}
The lifetime extension of the nuclear power stations is considered as an energy challenge worldwide. That is why, the risk analysis and the study of various effects of different factors that could potentially prevent safe long term operation are necessary. These structures, often of great dimensions, are subjected during their life to complex loading combining varying mechanical loads, multiaxial, with nonzero mean values associated with temperature fluctuations and also PWR environment. Based on more recent fatigue data (including tests at $300^{\circ} \mathrm{C}$ in air and PWR environment, etc...), some international codes (RCC-M, ASME and others) have proposed and suggested a modification of the austenitic stainless steels fatigue curve combined with a calculation of an environmental penalty factor, namely Fen, which has to be multiplied by the usual fatigue usage factor. The aim of this paper is to present a new device "FABIME2E" developed in the LISN in collaboration with EDF and AREVA. These new tests allow quantifying the effect of PWR environment on disk specimen. This new device combines the structural effect like equi-biaxiality and mean strain and the environmental penalty effect with the use of PWR environment during the fatigue tests.
\end{abstract}

\section{INTRODUCTION}

The question of assessing the margins and safety factors in the fatigue analyses which are widely used today (ASME BPV III, RCC-M, JSME, EN-13445-3, etc... [14]) is a very challenging one.

The fatigue rules used today in the nuclear industry were initially built and integrated into the ASME code in the 1960 's. Establishing fatigue rules is a challenge in itself since fatigue degradation depends on the wear of components which undergo repeated cycling: fatigue tests can therefore be very long and costly, if led on fullsize components. As a result, the testing is in practice conducted on small laboratory specimens, which then triggers the question of how to extrapolate results to a full size component. Another difficulty is that the rules need to remain easy to apply in order to be applied for industrial engineering calculations. Since 2007, the USA with the NUREG/CR-6909 [1], have now included the evaluation of environmental effects in their official regulation. Indeed, on the curves presented in Figure 1 and Figure 2, the PWR water environment effect on the fatigue lifetime of material used in the manufacture of reactor components are illustrated.

The 304L and the 316L stainless steels are used for the manufacturing of the pressurized water reactors (PWR). Many components of this type of reactors are subjected to a multiaxial thermo-mechanical cycling [5] and [12]. Therefore, the multiaxial fatigue assisted by environment is considered as one of the possible degradation mechanisms affecting the life of the PWR components.

Based on more recent fatigue data (including tests at $300^{\circ} \mathrm{C}$ in air and PWR environment, etc...), some international codes (RCC-M, ASME and others) have proposed and suggested a modification of the austenitic stainless steels fatigue curve combined with a calculation of an environmental penalty factor, namely Fen, which has to be multiplied by the usual fatigue usage factor. Unfortunately, testing on structures representative of real plant components is expensive but should be today increased to help contribute to the general understanding of the various aggravating effects [6-10]. In order to obtain fatigue strength data under structural loading, biaxial test means with and without PWR environment were developed at LISN [11] [13-14].

Two kinds of fatigue devices have been developed. Within the same specimen geometry, structural loads can be applied in varying only the PWR environment. The first device (FABIME2) is devoted to studying the effect of biaxiality and mean strain/stress on the fatigue life. A second and new device named FABIME2e and based on the first device, is for the study of the impact of the environmental effects. With these new experimental results, we will be able to study the interaction between PWR environment and multiaxial loading 


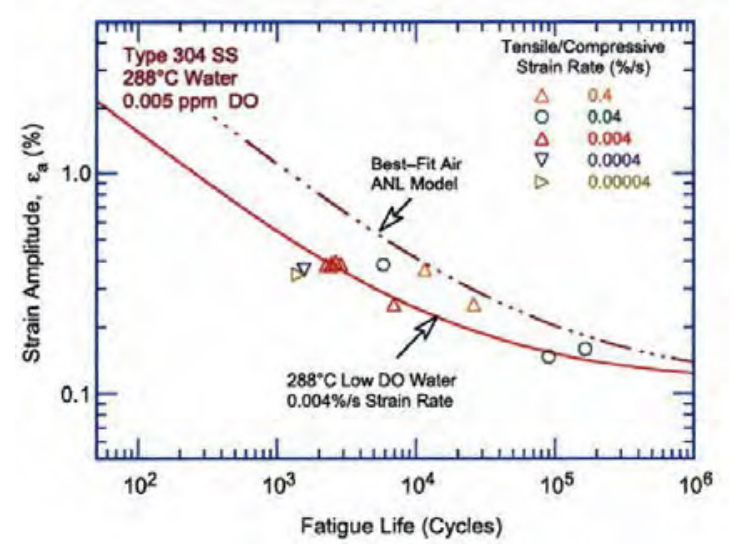

Fig. 1: Fatigue life of 304L steels in PWR water compared with the ANL model Air curve.

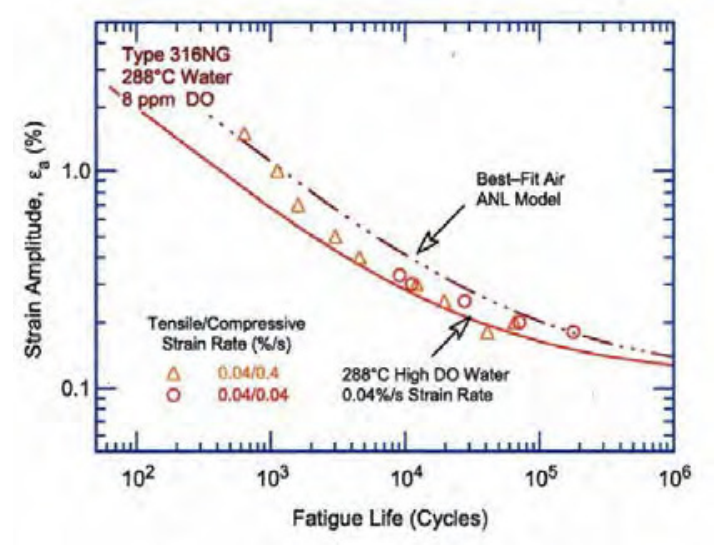

Fig. 2: Fatigue life of $316 \mathrm{LN}$ steels in PWR water compared with the ANL model Air curve.

\section{THE FIRST EXPERIMENTAL DEVICE}

Apply an equibiaxial state loading without mean stress or strain is the objective of this testing. Indeed, we tried to obtain a negative load ratio in order to get the same results as the uniaxial fatigue data and eliminate the residual strain. In this study, equibiaxial state loading generated from spherical bending has been considered. It was used to optimize the geometry of a disk specimen refined in its center. It was used as a circumferentially embedded diaphragm with an applied pressure on both sides in order to obtain an equivalent strain in each loading direction in the plane (Figure 3).

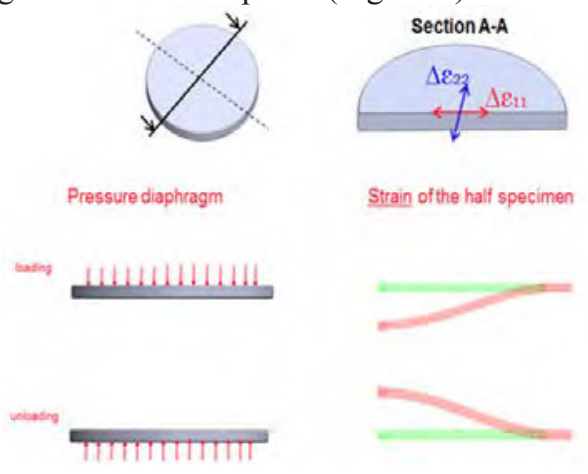

Fig. 3: Principle of the equibiaxial fatigue test.

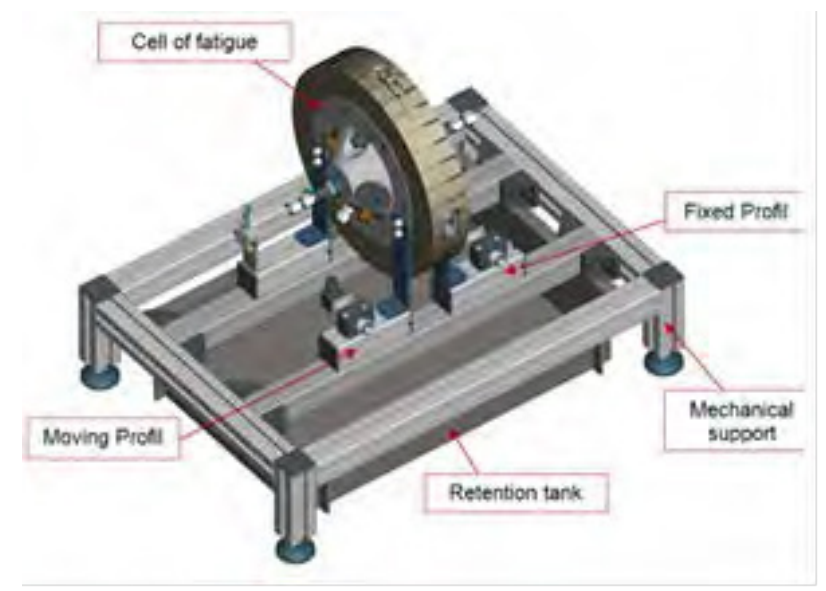

Fig. 4: View of the spherical bending device fatigue cell.

The experimental device called «FABIME2» is divided into four parts:

- Fatigue cell which contains the spherical bending specimen (Figure 4),

- Pressure generating system until 100 bars,

- Electrical enclosure,

- Dedicated CEA in house software developed under LABVIEW that provides control and acquisition data during the tests.

Two half-shells allow the positioning of the spherical bending specimen. Seal and embedment are realized by bolting these two parts.

Maximum experimental conditions are 100 bars for the pressure and $90^{\circ} \mathrm{C}$ for the temperature. An alternative differential pressure between the two sides of the disk specimen is applied during the fatigue test.

To ensure well-defined experimental conditions, various measuring means are located symmetrically at the two half-shells:

- Pressure sensor with a measuring range between 0 to 100 bars

- Type $\mathrm{K}$ thermocouple to measure the temperature of the fluid inside the fatigue cell

- Displacement sensor (LVDT) to measure the deflection at the center of the spherical bending specimen. This sensor has a $5 \mathrm{~mm}$ range. Realizations of surface observations after the fatigue test show that the contact between LVDT and specimen is negligible (no fretting). No crack initiation is also observed directly under the LVDT.

- Two visualization windows on each half-shell, oriented at $45^{\circ}$ with a diameter of $20 \mathrm{~mm}$. The constitutive material is borosilicate glass with a permissible operating pressure of 100 bars.

The fatigue cell was built under European Security directives (Machines 2006/42/CE, Pression 97/23/CE).

\section{THE EXPERIMENTAL RESULTS AND INTERPRETATION}

Biaxial fatigue tests were carried out on two austenitic stainless steels: "316L THY", and "304L CLI". The first 
material has been provided by Thyssen Krupp Materials France as a $15 \mathrm{~mm}$ thickness rolled sheet. The second material supplied by EDF is characterized by a thickness of $30 \mathrm{~mm}$ rolled sheet.

An interpretation of the equibiaxial fatigue tests with the definition of the equivalent strain used in the nuclear industry are made. This is an important step to evaluate the impact of an equibiaxial loading on the fatigue life. All tests performed in this study are carried out with imposed displacement with alternating load (displacement load is symmetrical), means value of the displacement is null corresponding to a load ratio $\mathrm{R}=-1$. To compare the experimental data obtained from uniaxial and equibiaxial tests, it is necessary to define a total equivalent strain. Two definitions of equivalent strain are proposed: the first is based on the definition of von Mises (used in the RCC-MRx) and the second on the definition of Tresca (used in the RCC-M, RSE-M).

Thus, the first equivalent strain used is the von Mises equivalent strain defined by the following equation:

$$
\Delta \varepsilon_{e q}^{V M}=\sqrt{\frac{1}{1+v \prime}\left(\Delta \varepsilon_{d}: \Delta \varepsilon_{d}\right)}=\frac{2}{3} \frac{(1+v \prime)}{(1-v \prime)} \Delta \varepsilon_{1}
$$

with the strain deviatoric component:

$$
\Delta \varepsilon_{d}=\Delta \varepsilon-\frac{1}{3} \operatorname{tr}(\Delta \varepsilon)
$$

with $\varepsilon 1$ the principal strain and $v$ ' the "real" Poisson's ratio (elastic $v=0.3$ and plastic part $v=0.5$ ).

The second equivalent strain is the Tresca equivalent strain defined by the following equation:

$$
\Delta \varepsilon_{e q}^{T}=\frac{1}{1+v \prime} \operatorname{Max}\left|\varepsilon_{i}-\varepsilon_{j}\right|
$$

The proposal approach to determine the level of the equivalent strain for each FABIME2 test is as follows:

- Determination of the value of the radial strain corresponding to the imposed deflection from the strain-deflection calibration curve obtained in the paper [14]. With a similar mechanical behavior, the calibration curve can be used for the two materials.

- Determination of the von Mises or Tresca equivalent strain from the relation between the radial strain and the equivalent strain (von Mises or Tresca). This relation has been determined by elasto-plastic calculation of the fatigue test.

This method has been applied to the equi-biaxial fatigue tests presented earlier. The corresponding fatigue life curves are compared to that under uniaxial loading in Figure 5. It appears that there is no impact of equibiaxial fatigue for the two types of materials, considering von Mises equivalent strains.

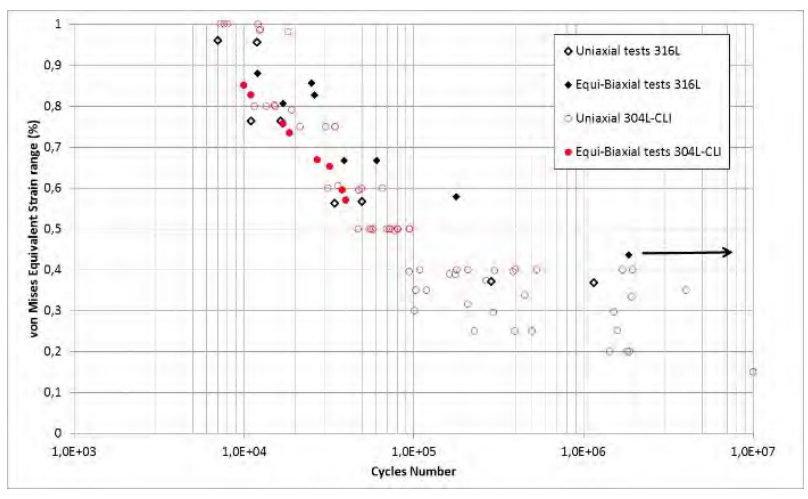

Fig. 5: Fatigue data obtained on the two austenitic stainless steels (316L and 304L-CLI).

\section{SPECIFICATION OF THE NEW DEVICE FABIME2E}

The second fatigue testing device (FABIME2e, e for environment) has been developed to apply on the same specimen geometry the same structural loads and to only change the testing environment to a PWR environment. Compared to FABIME2, specification changes for FABIME2e device mainly focused on the following points:

- Specimen is in contact with a PWR environment,

- An operating temperature of $340{ }^{\circ} \mathrm{C}$,

- A maximum pressure of up to $350 \mathrm{bar}$,

- Monitoring and adjustment of dissolved hydrogen level during testing,

- A perfectly flat and reproductive clamping of the specimen.

With these severe experimental conditions, four major technical difficulties had to be taken into account:

- The cohabitation of the PWR environment with the hydraulic oil at room temperature and 100 bar maximum,

- The PWR environment temperature stability: variations less than $1{ }^{\circ} \mathrm{C}$ up to several weeks should be allowed in order to detect the initiation of cracks,

- Monitor and adjust if necessary dissolved hydrogen level,

- The perfect sealing of the device during the tests.

A double cylinder system has been proposed to separate PWR and hydraulic fluids to apply a mechanical loading to the specimen (Figure 6). A double acting cylinder would be moved by the hydraulic unit. Its movement would be mechanically transmitted (by the water incompressibility) to a primary cylinder to modify the volume of the PWR environment contained in each halfshell. Similarly to FABIME2 this system applies a differential pressure, of up to 100 bars, to the specimen. The difference here is that the pressure variation around the specimen is between 150 and 350 bars, respectively the biphasic threshold of the PWR environment and the maximum pressure allowed by FABIME2e. 


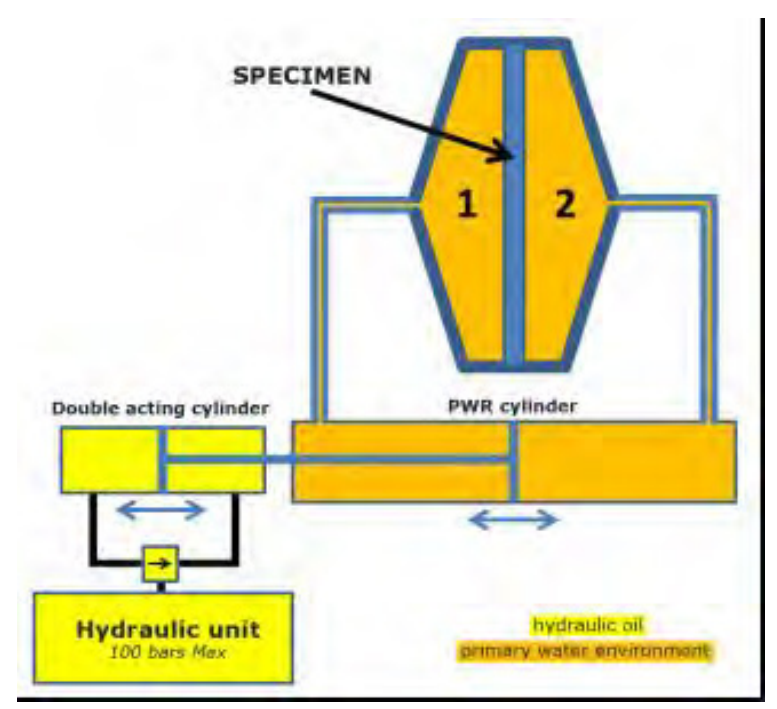

Fig. 6: Double cylinder system for separation of PWR and Hydraulic fluid.

If the required pressure in the PWR environment is obtained by its constraint thermal dilation, this phenomenon must be avoided during the test. A variation of $1{ }^{\circ} \mathrm{C}$ would cause a variation of several bars around the specimen. These pressure fluctuations may compromise the detection of the initiation of cracks by compliance. A stronger fluctuation could even lead the PWR environment under its biphasic threshold. This would require a test stop. To avoid this, a temperature regulation system with a great stability was required.

The evolution of the chemical composition of the environment was one of the concerns for this new bench. Hydrogen is the most volatile part of this, so the ability to measure and if necessary adjust its level was needed. In the end, the requested instrumentation would enable the monitoring of the evolution of the following data, for each half-shell: temperature, pressure, displacement and dissolved hydrogen level.

\section{THE NEW EXPERIMENTAL DEVICE: FABIME2E}

The manufacturing and commissioning of FABIME2e was ensured by a French company: TOP INDUSTRY. The maximum experimental conditions of the new device are 350 bars and $340^{\circ} \mathrm{C}$.

The main features of this new device are:

- A cell consisting of two half shells for holding the specimen,

- A clamping system for the cell,

- A sealing system compatible with the PWR environment,

- A closed PWR environment circuit,

- A « double cylinder » system to apply the mechanical solicitations on the specimen,

- An accurate and reliable heating system,

- A system for measuring and adjusting the level of dissolved hydrogen in the PWR environment,

Instrumentation for temperature, pressure, displacement.

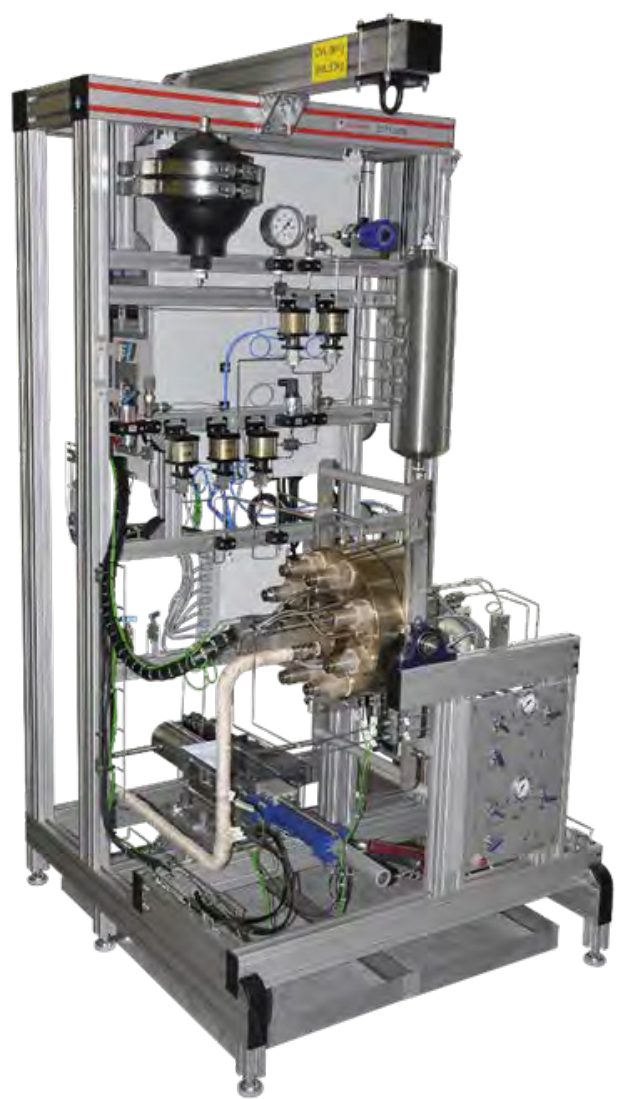

Fig. 7: View of the fatigue new bending device FABIME2e.

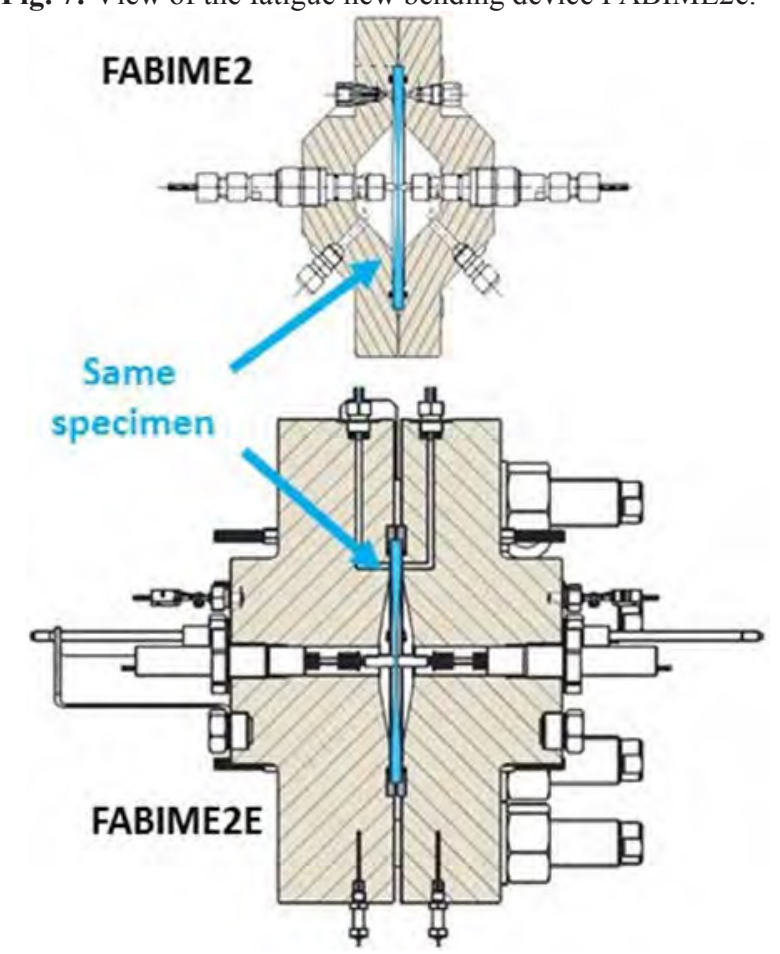

Fig. 8: Comparison between FABIME2 and FABIME2e fatigue cells (same scale and specimen geometry).

Because of much higher pressures and temperatures, the FABIME2e cell has more imposing dimensions than its predecessor FABIME2 (Figure 8). However, the specimen geometry remains absolutely identical to be usable indifferently on the both test benches. 
Each half- shell has the following instrumentation:

- Two type $\mathrm{K}$ thermocouples, positioned at the top and bottom,

- A pressure sensor with a 0-400 bar range,

- A LVDT compatible with the PWR environment, with a $\pm 5 \mathrm{~mm}$ range to measure the deflection of the specimen,

- Two hydrogen sensors Pd -Ag from AREVA: one for measuring and one for adjusting the dissolved hydrogen level if necessary.

Two metal rings are disposed on each side of the specimen to ensure the sealing of the cell during the test period. Clamping is achieved by means of a hydraulic clamp machine to ensure flatness, sealing and repeatability. Eight heavy section attachment studs ensure the two half shells clamping around the specimen. FABIME2e cell has a $100 \mathrm{ml}$ volume. After filling the cell and high-pressure pipes the heating achieves the desired pressure because of the thwarted thermal dilation of the primary water.

Eight cartridge heaters with an output of $250 \mathrm{~W}$ each are located on each half-shell to reach the nominal temperature of $340^{\circ} \mathrm{C}$. The temperature rise is carried out at a maximum rate of $1^{\circ} \mathrm{C} / \mathrm{min}$. The maximum allowable temperature is $400{ }^{\circ} \mathrm{C}$. Although the primary cylinder is at room temperature, a part of the pipes which connects it to each half-shell is also temperature controlled. Two EUROTHERM controllers (NANODAC model) ensure the regulation of the 4 heating zones.

The same hydraulic group provides oil to both FABIME2 and FABIME2e test benches. As shown in Figure 6, a hydraulic cylinder allows transmitting loadings to the primary cylinder to deform the specimen.

As it is possible to do with the bench FABIME2, pressure, displacement or strain control is allowed. The development of the control software in the CEA laboratory allows great flexibility: cycling shape, holds, control mode modifications, mean pressure or strain. The low-level tasks such as security management, hydraulic control and data reading require determinism and speed of processing. That is the reason why they are devolved to real-time autonomous software running on a COMPACT RIO device (NATIONAL INSTRUMENT). The tests management, acquisition and data analysis are performed by software running on a conventional PC. This second software controls each test sequence: from the filling of the PWR fluid untill the crack initiation estimation through sending orders to the CRIO software and the EUROTHERM controllers.

\section{FIRST EQUIBIAXIAL FATIGUE TESTS UNDER PWR CONDITIONS}

A first series of test was carried out with the FABIME2e device. One of the objectives of these tests was the validation of the concept of the stages separation (oil / primary water) via the intermediate cylinder. The second objective was to demonstrate the criterion for detecting a crack initiation in the centre of the disk specimen.

This series consists of tests with different conditions (pressure and temperature). The environment was composed of distilled water.

Before fatigue tests, a LVDT calibration phase was realized at ambient temperature and at $300^{\circ} \mathrm{C}$ with a specific specimen. It consists of hollowed specimen out in the centre and contains a zipper with different calibrated height steps (Figure 9).

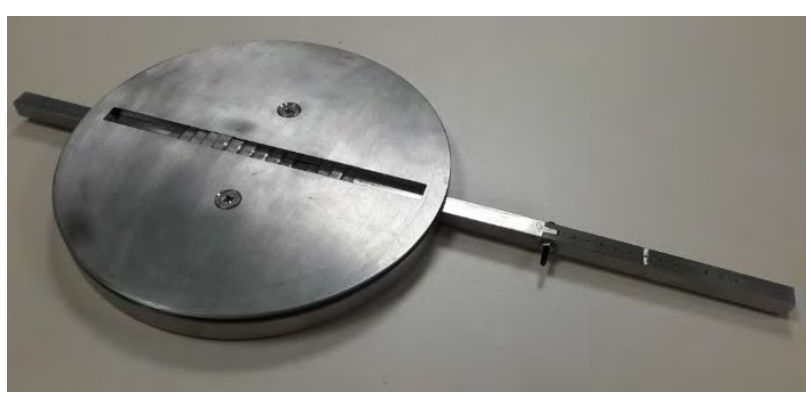

Fig. 9: Dedicated calibration specimen used to calibrate the LVDT at ambient temperature and at $300^{\circ} \mathrm{C}$.

An important software development work has been undertaken to obtain LVDT evolutions without jerk or jump (Figure 10).

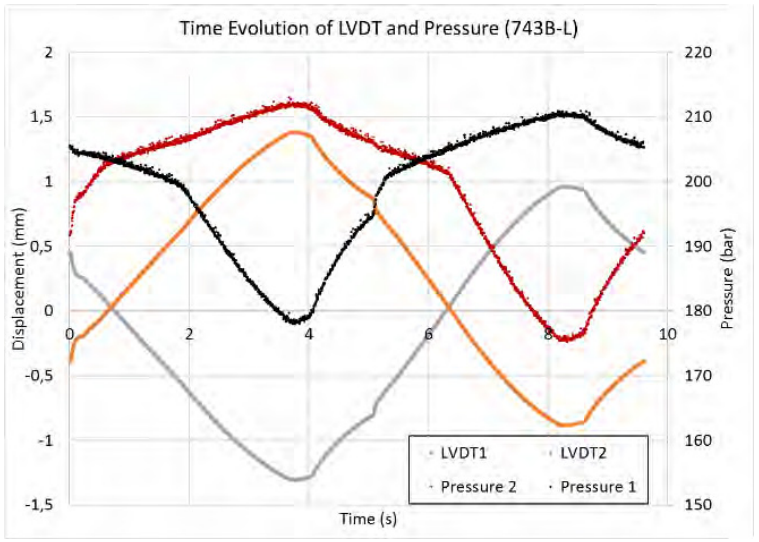

Fig. 10: Time evolution of the displacement (LVDT) and the applied pressure for a spherical fatigue test.

The experimental conditions are: an initial pressure of 50 , and 250 barss, an ambient temperature $\left(30^{\circ} \mathrm{C}\right.$.) or $300{ }^{\circ} \mathrm{C}$ and an imposed deflection of $1.4 \mathrm{~mm}, 1.3 \mathrm{~mm}$ and $1.2 \mathrm{~mm}$.

The principle of detection of fatigue crack initiation is achieved by studying the evolution of the pressure applied to the fluid via the intermediate cylinder to obtain the imposed deflection. When a "significant" change in this pressure is observed (Figure 11), the test is stopped, the test piece is take off and observed. The crack initiation criterion is defined as having a crack length of $5 \mathrm{~mm}$ at the surface on the side 2 (Figure 12), which corresponds to a (downward) variation in the pressure of the order of 1 to 2 bars. 


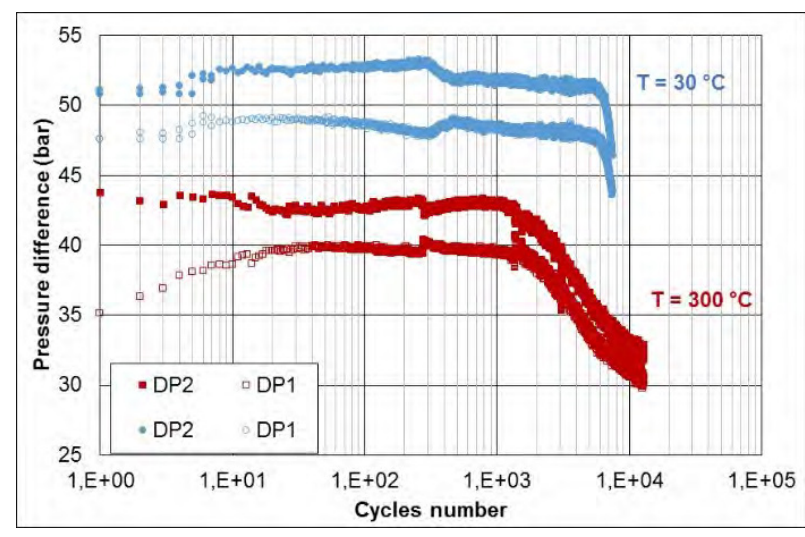

Fig. 11: Evolution of pressure during tests with two temperature conditions $\left(\mathrm{T}=30^{\circ} \mathrm{C}\right.$ and $\left.300{ }^{\circ} \mathrm{C}\right)$ in distilled water environment.

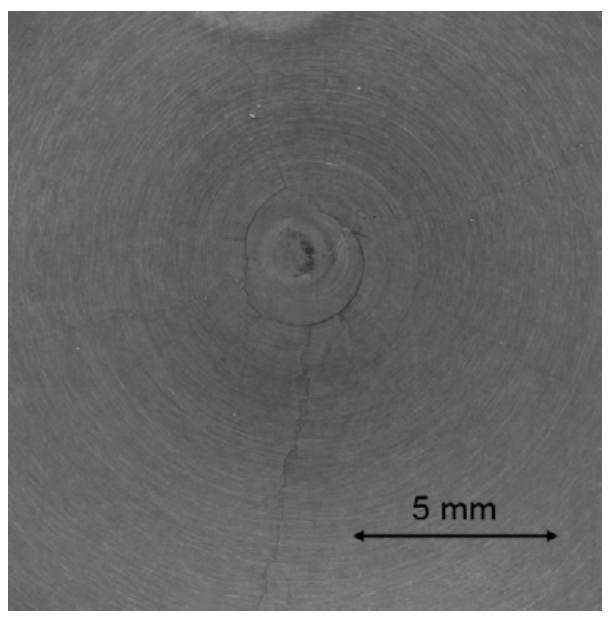

Fig. 12: View of the fatigue crack initiation under PWR conditions on spherical bending specimen.

On the figure 13, the experimental results of spherical bending fatigue tests are represented for different conditions and in distilled water environment. On these first results, the environment effect is highlighted, so for a $5 \mathrm{~mm}$ length surface crack, the number of cycles is reduced to a factor $3\left(7500\right.$ cycles à $30^{\circ} \mathrm{C}$ to 2500 cycles at $\left.300^{\circ} \mathrm{C}\right)$.

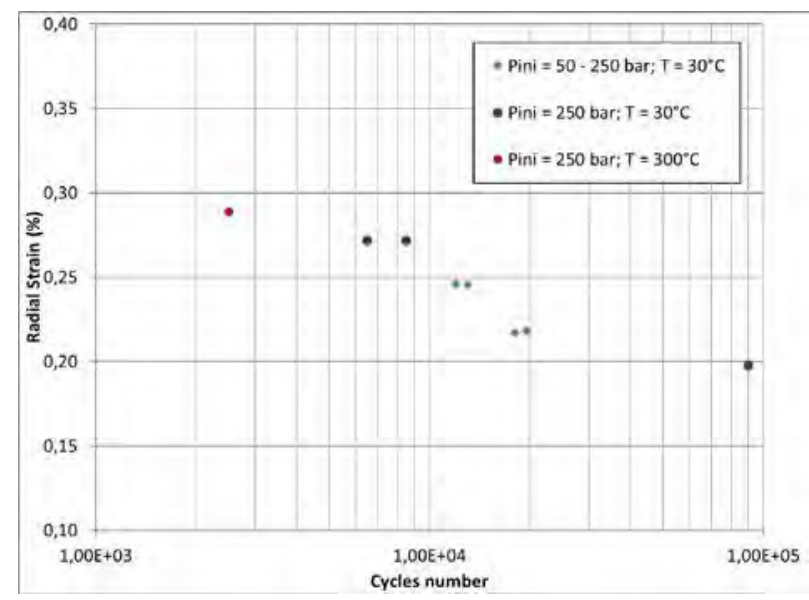

Fig. 13: Experimental data spherical fatigue tests obtained with FABIME2e device for different conditions (temperature, pressure).

\section{CONCLUSIONS}

This paper is focusing on the description of two kinds of experimental devices to perform fatigue tests on specimen with or without the effect of PWR environment.

The first device (FABIME2) is devoted to study the effect of biaxiality and mean strain/stress on the fatigue life. Biaxial fatigue tests are carried out on two austenitic stainless steels: 316L THY and 304L CLI. The results obtained show that crack initiation under an equibiaxial loads have a low impact on the fatigue life, which remains in the field covered by the design curve defined and used in the codification.

A second and new device named FABIME2e is under development for the study of the impact of the environmental effect. This device will study the impact of the equibiaxial loadings with a primary water environment PWR $\left(300^{\circ} \mathrm{C}\right.$ with a permanent pressure of 140 bars). The first experimental tests consolidate the conception of this device (FABIME2e).

F. Datcharry and M. Rousseau from CEA is very greatly acknowledged for his participation in the FABIME2E conception.

\section{References}

1. Chopra O.K. and Shack W.J. (2007), NUREG/CR6909, Rev. 0, "Effect of LWR Coolant Environments on the Fatigue Life of Reactor Materials,".

2. RCC-M (2007) - Design and Construction Rules for mechanical components of nuclear PWR islands 2007 edition with addenda in 2008, 2009 and 2010.

3. EN-13445-3 V1 standard (2014), "Unfired pressure vessels - Part 3: Design,".

4. RCC-MRx (2012) «Règles de Conception et de Construction des Matériels Mécaniques des Installations Nucléaires applicables aux structures à haute température et à l'enceinte à vide ITER ", AFCEN Code, Association Française pour les Règles de Conception et de Construction des chaudières Électronucléaires. www.afcen.com.

5. Fissolo A. et al. (2009), "Crack Initiation under thermal fatigue: an overview of CEA experience, Part 1: thermal fatigue appears to be more damaging than uniaxial isothermal fatigue", Int. Journal of Fatigue, vol.31(3), p.587-600.

6. Lefebvre D.F. (1989), "Hydrostatic Pressure effect on Life Prediction in Biaxial Low-cycle fatigue", Biaxial and Multiaxial Fatigue, EGF 3.

7. Itoh T., Sakane M. and al. (2006)," A design procedure for assessing low cycle fatigue life under proportional and non-proportional loading", Int. Journal of Fatigue, 28.

8. Parsons, M. W. Et Pascoe, K. J. (1975), "Development of a biaxial fatigue testing rig", Journal of Strain Analysis, 10, $N^{\circ}$ 1, p1-3. 
9. Shimada H., Shimizu K., Obata M., Chikugo K. \& Chiba, M. (1976), "A new biaxiaI testing machine for the flat specimen and a fundamental study on the shape of the specimen", Technology Reports, Tohoku Univ., 42. $\mathrm{N}^{\circ}$ 2, p351-369.

10. Poncelet M. et al. (2010), "Biaxial High Cycle Fatigue of a type 304L stainless steel: Cyclic strains and crack initiation detection by digital image correlation", European Journal of Mechanics A/Solids.

11. Bradai S. et al. (2013), PVP2013-97200, "Crack Initiation under Equibiaxial Fatigue, Development of a particular Equibiaxial Fatigue Device."

12. De Baglion L. (2006), " Comportement et endommagement en fatigue oligocyclique d'un acier inoxydable austénitique $304 \mathrm{~L}$ en fonction de l'environnement (vide, air, eau primaire REP) à $300^{\circ} \mathrm{C}$ », Thèse de l'Ecole Nationale Supérieure de Mécanique et d'Aérotechnique.

13. Bradaï S., Gourdin C. and Gardin C. (2014), "Study of crack propagation under fatigue equibiaxial loading", PVP2014-28417, ASME PVP.

14. Bradaï S., Gourdin C. and al. (2015), "Equi-Biaxial Loading Effect on Austenitic Stainless Steel Fatigue Life", PVP2015-45293, ASME PVP. 